\title{
O “Clã da Lapa” na formação da classe dominante paranaense
}

\author{
Fernando Marcelino Pereira ${ }^{1}$
}

\begin{abstract}
Resumo: No século XIX, as classes dominantes no Paraná foram formadas pelas famílias tradicionais da Lapa, Castro, Paranaguá e Antonina que passaram a viver em Curitiba, dedicando-se à industria ervateira e ao aparelho de Estado. Este artigo tem como objetivo analisar o papel do "Clã da Lapa" na formação da classe dominante do Paraná (todas as famílias com origens históricas no latifúndio escravista da Lapa - Ferreira, Amaral, Pacheco, Lacerda, Correa, Braga, Rezende, Cunha, Suplicy, Pereira, Coelho, Porto, Westphalen, entre outras - aparentadas entre si), formando uma ampla rede familiar que ocupou os centros de poder da Lapa e do Paraná.
\end{abstract}

Palavras-Chave: Classe dominante. Paraná. Lapa. Clã.

\section{The "Clan of Lapa" in the formation of the paranaense ruling class}

Resume: In the 19th century, the dominant classes in Paraná were formed by the traditional families of Lapa, Castro, Paranaguá and Antonina, who began to live in Curitiba, dedicating themselves to the iberian industry and the State apparatus. This paper aims to analyze the role of the "Clan of Lapa" in the formation of the dominant class of Paraná (all families with historical origins in the slavery like Ferreira, Amaral, Pacheco, Lacerda, Correa, Braga, Rezende, Cunha, Suplicy, Pereira, Coelho, Porto, Westphalen, among others - related to each other), forming a wide family network that occupied the power centers of Paraná and Lapa.

Key words: Ruling class. Paraná. Lapa. Clan.

*Enviado em 30/05/2018.

*Aceito em 15/06/2018.

O início do século XVIII marcou a ocupação da região dos Campos Gerais, inicialmente por famílias originárias de São Paulo, Santos e Paranaguá. A região da Lapa, nos Campos Gerais, foi chamada inicialmente de Freguesia de Santo Antônio da Lapa, e estava sob a jurisdição da então “vila de Curitiba". Em 1806 foi denominada Vila Nova do Príncipe e em 1872 foi elevada à categoria de cidade sendo nomeada Lapa.

Como vigário local foi indicado o padre João das Silva Reis, filho dos reinóis João Pereira Braga e Josefa Gonçalves da Silva. Seus pais foram os primeiros sesmeiros a se estabelecer com morada efetiva nos Campos Gerais (WESTEPHALEN, 1991, p. 178). O parentesco deste casal com Manoel Gonçalves do Aguiar, Sargento-Mor e Comandante da Praça de Santos, provavelmente contribuiu para que João Pereira Braga fosse escolhido para administrar as fazendas que o oficial

\footnotetext{
${ }^{1}$ Bacharel em Relações Internacionais pelo Centro Universitário Curitiba (UNICURITIBA), mestre em Ciência Política e doutorando em Sociologia pela Universidade Federal do Paraná (UFPR). E-mail: fernandomarcelinopereira@gmail.com
} 
possuía na região. Desde 1727, João também era proprietário dos Campos de Tibagi e, em 1742, adquiriu a sesmaria da Palmeira (WESTEPHALEN, 1991, p.178). O vigário exercia seu ministério na localidade onde estavam não apenas seus pais, mas também seus irmãos e irmãs, filhos e genros, e sucessivamente os descendentes, assumindo a liderança eclesial e política local. Desde a primeira lista nominativa de habitantes e até a de 1798, seus familiares consangüíneos constam dentre os que detêm os principais cargos nas milícias e nas companhias de ordenança, exercendo funções que iam desde alferes, tenentes, sargentos e, especialmente, de capitães. Em 1777, Joze dos Santos Pacheco foi indicado como feitor da freguesia. Dois anos mais tarde, Francisco Teixeira Coelho assumiu o posto de capitão de ordenança, até então ocupado por Antonio Gonçalves do Reis, que estava ausente por muito tempo, no posto de alferes. Domingos Pereira da Silva recebeu o cargo de almotacel (fiscal e aferidor de preços). Foi o Capitão Francisco Teixeira Coelho que, em 1806, quem teve a iniciativa de passar uma procuração aos militares para que requeressem a elevação da Freguesia à Vila. A esposa de Francisco, Gertrudes, era neta do primeiro sesmeiro da região. Do casamento descendem Francisco José Correia (primeiro bacharel paranaense em Coimbra), José Francisco Correa (primeiro médico), Dâmaso José Correia (primeiro padre), Joaquina (casa-se com Manoel Antônio da Cunha, o primeiro prefeito da Lapa) (VALLE, 1983). Conforme matéria da Gazeta do Povo:

\footnotetext{
Era o ano de 1797, quando relatos dão conta que ao lado de moradas nobres estavam aqueles “caboclos". As primeiras famílias proprietárias de sesmarias, marcadas em 1769, dadas pelo governo, eram os Costa, da Luz, dos Reis e Rodrigues. Estes porém nunca moraram naquelas paragens. Os primeiros moradores eram paulistas ou portugueses. Os paulistas na sua maioria da região litorânea, de Itanhaém, os Collaço, Góes, Leme da Silva, os Gonçalves Siqueira, Gonçalves Ribeiro. Como portugueses os Lopes Cascaes vindos de Cascaes, os Coelho, Pereira, Lara, Barreyros, Almeida, Silva, Souza, Araújo, França. Chaves, Reis, etc (1º livro de batizados - 1769 - 1797). No auto de ereção da Vila (1806) temos: Oliveira Cercal, Carvalhos Fontes, Pereira, Teixeira Coelho, Moira Leite, Dinis Romano, Gomes Pereira, Silva Sampaio, Souza Fagundes, Alves Natel, Monteiro de Azevedo, Dias Pereira, Borges da Silva, Vieira Gonçalves, José Pinto, Rodrigues de Souza, Ferreira de Castilhos etc. Em 1769 a Lapa contava com 100 famílias (Livro do Tombo - 1882) “ de portugueses e de sangue limpo". Segundo o pároco à época, a cidade contava ainda com pelo menos $50 \%$ de mulatos e mestiços. Há também a figura do "gaúcho dos campos gerais ou "monarca da coxilha" que ajudou na formação cultural, fruto da passagem das tropas pela região. Outros nomes da genealogia Lapeana são os Antonio da Cunha, Pereira Rezende, Guilherme Virmond, Suplicy, Westphalen, Lacerda, Wiedmer,Santos Lima, os Ferreira, os Porto, etc. Fruto das imigrações encontramos ainda os de origem russa-alemã, alemães, poloneses, sírios, italianos, etc. Os nomes são: Baggio, Cavallin, Calderari, Candeo, Beraldi, Bortoleto, Pazzinato, Mollinari, Pauli, Zappa, Favaro, Sossela, Pierin, Campanholo, Follador, Gluck, Scandelari, Ganzert, Ehlke, Vidal, Reuth, Moskalewski, Ritzmann, Dietrich, Tirka, Aracheski, Sera, Klostermann, Hammerschimidt, Schulz, Wille, Good, Kuss, Paquet, Stinglin, Murbach, Kaled, Zarur, Weinhardt, Notto, Burda, Surek, Abagge, Maurer, Deuqueche, Kaseker, etc ${ }^{2}$.
}

\footnotetext{
${ }^{2}$ População da Lapa: Tipos e Costumes. Nogaroli, Lamb. Corção, Isabel. Lacerda, Maria T. B. Gazeta do Povo. 28/06/1981.
} 
No final do século XVIII quase toda a área estava povoada, embora com propriedades muito grandes para comportar a pecuária expansiva, o que levou ao crescimento da pecuária na economia regional. Conforme Carlos Vicente Ferreira, quem possuía recursos investia-os na compra de gado no Rio Grande do Sul, para revender na feira de Sorocaba, surgindo assim o tropeiro, intermediário entre o criador e o comprador. O grande tropeiro tinha capital para sustentar a longa viagem desde a compra do gado no Rio Grande, a recuperação nos Campos Gerais e a revenda em Sorocaba. O pequeno tropeiro às vezes, simplesmente reduziam-se a condutores das tropas (FERREIRA, 1996, p. 41). Com a baixa na produção de metais preciosos em Minas Gerais houve uma desagregação do sistema comercial dos fazendeiros (tropeiros) dos Campos Gerais, conseguindo se manter até o final do século XVIII quando foi criada a rodovia Centro-Sul do país (Minas Gerais, Rio de Janeiro e São Paulo). Em termos quantitativos é exemplar a passagem seguinte: "a feira de Sorocaba, que ainda, em 1860 negociava 100 mil animais, não movimentava mais que 5 mil nos anos finais do século passado [XIX]. Com o ciclo dos tropeiros arquivado, a economia ficou estagnada" (ibidem).

Maria Tarcisa Bega lembra que nos Campos Gerais as relações sociais não diferiam muito do modelo dominante no Brasil, assentado na propriedade rural, cujo trabalho era executado pela mão de obra escrava. Este modelo predominou em toda a área de criação de gado, cuja atividade não possibilitou um incremento populacional significativo e nem fazendas com escravaria expressiva. Mesmo assim, sabe-se que as grandes fazendas de criação de gado na Lapa possuíam escravos negros. Sabe-se que os escravos construíram a antiga Capela onde se encontra hoje a Igreja de São Benedito e os muros do cemitério municipal. Eram nos núcleos mais pecuaristas, como Castro, Lapa e Palmeira, os escravistas sem terras revelaram peso menor dentro da classe formada pelos senhores de escravos, por mais que na localidade também havia oferta de trabalhos especializados nos diversos ofícios mecânicos e nas atividades associadas ao trato com o gado (BEGA, 2001, p.91).

Os fazendeiros, também conhecidos por senhores dos Campos Gerais, estavam associados aos latifúndios agropastoris, pecuária bovina e invernagem e comércio de muares do Rio Grande do Sul além de estavam atrelados também ao trabalho escravo, ao incentivo à imigração europeia e ao monopólio da representação política, pois os especialistas (bacharéis, médicos e engenheiros) filhos dos fazendeiros - passaram a ocupar grande parte dos empregos públicos e dos cargos de representação política da Província.

David dos Santos Pacheco, primeiro e único Barão dos Campos Gerais, (Lapa, 28 de junho de 1810 - 1 de novembro de 1893) foi comerciante de gado e político da Lapa. Ocupou terras 
e preparou-as para que as "comitivas" realizassem paradas de descanso e engorda dos animais em suas instalações, já que no primeiro trecho desta viagem os animais perdiam peso e consequentemente se desvalorizavam. Desta maneira ampliou suas posses e constituiu fazendas de criação no Rio Grande do Sul, em Rio Negro e Itapetininga. David Pacheco foi um dos maiores tropeiros do Brasil no século XIX. O prestígio adquirido como comerciante de gado levou-o para a política, sendo ele um dos fundadores do Partido Liberal e exercendo cargos de nomeação e eletivo, a começar pela presidência da Câmara Municipal da Lapa e logo após deputado provincial, na primeira eleição da recém criada província. David foi um dos que batalharam pela emancipação política da $5^{\circ}$ comarca de São Paulo, chegando a exercer o cargo de vice-presidente do Paraná Tornou-se comandante da Guarda Nacional em Curitiba e durante a Guerra do Paraguai, organizou um batalhão de voluntários com 150 soldados que foram fardados e equipados à sua própria custa. Casou com Ana Pacheco de Carvalho, filha de Sebastião José Vaz de Carvalho e de Inácia Maria dos Santos. Foi sogro de Manuel Alves de Araújo, Deputado provincial do Paraná de 1864 a 1869. Foi deputado geral de 1878 a 1889, secretário e presidente da Câmara dos Deputados em 1884. Também foi ministro dos Transportes de 21 de janeiro a 3 de junho de 1882. Irmão do deputado provincial, comendador Antônio Alves de Araújo e do brigadeiro e deputado provincial Hypólito Alves de Araujo.

Foi no planalto de Curitiba que se iniciou a produção de erva-mate, produto que iria revolucionar a economia paranaense por mais de um século, logo se espalhando por cidades dos Campos Gerais, como a Lapa. A produção da erva-mate de exportação vai se transformar em esteio da economia paranaense, sobretudo no período provincial. Foi uma época de ouro. Houve períodos em que o produto chegou a representar $85 \%$ da economia da província (WACHOWICZ, 1977, p. 96). A erva-mate produzida nos planaltos paranaenses passava pelo processo industrial no litoral, logo, a oligarquia de Morretes, Paranaguá e Antonina beneficiava-se de maior parte do lucro. A ascensão da oligarquia litorânea representou a relativização do poder da oligarquia campeira.

Até o penúltimo quartel do século XIX, o grupo ligado ao latifúndio dos Campos Gerais controlava a maior parte do poder econômico e do poder de governo no Paraná. Dessa região saíram diversas autoridades políticas que ocupavam espaços na administração pública. Havia tanem o grupo do litoral, atrelado ao comércio da erva-mate, porém com poder muito menor. Esse cenário começou a mudar a partir do último quartel do mesmo século, caracterizado por um processo de desagregação dos negócios agrários, bem como pelo crescimento substancial da industrialização da produção do mate. No plano econômico, houve retrocesso da força da oligarquia agrária e avanço da potência da 
oligarquia do litoral do Paraná (CAMPOS, 2013). Como nota Ribeiro, em junho de 1889, com a queda do gabinete conservador de João Alfredo e a ascensão do gabinete liberal do Visconde de Ouro Preto assume, no Paraná, o principal líder liberal, Jesuíno Marcondes de Oliveira. Marcondes, em conjunto com o Barão dos Campos Gerais e Manuel Alves de Araújo (genro do Barão) formavam "a mais poderosa oligarquia local durante todo o período da província do Paraná" (RIBEIRO, 1982, p. 71). Por outro lado, “o Partido Conservador era chefiado por Manuel Antonio Guimarães (Visconde de Nácar) e por Manuel Francisco Correia (senador do Império), ambos pertencentes também a poderosas famílias que no litoral controlavam o comércio importador e exportador da erva-mate" (RIBEIRO, 1982, p. 71).

Entre janeiro e fevereiro de 1894, a Lapa resistiu durante 26 dias as tropas federalistas que tentavam chegar a capital da recém declarada República do Brasil. O famoso combate, chamado Cerco da Lapa, é um dos capítulos mais importantes da história nacional. A batalha deu ao Marechal Floriano Peixoto, chefe da república, tempo suficiente para reunir forças e deter as tropas federalistas. Os restos mortais do General Carneiro, assim como de muitos outros que tombaram durante a resistência, estão sepultados no Panteon dos Heróis. Em janeiro de 1894, registra-se a invasão do Paraná pelos revolucionários federalistas vindos do Rio Grande do Sul, "sendo os principais focos da luta armada no Paraná: Paranaguá, atacada e tomada pela armada de Custódio de Mello. Tijucas do Sul, defendida por Adriano Pimentel, mas vencida pelas tropas de Gumercindo Saraiva, e a Lapa. Esta foi sitiada de 17 de janeiro a 11 de fevereiro, também pelas tropas legalistas comandadas pelo Coronel Antonio Ernesto Gomes Carneiro, após duros combates e a morte do seu próprio comandante, capitulou com todas as honras de guerra” (WESTPHALEN, 1977, p.60). Ao todo foram 639 homens entre forças regulares e civis voluntários, lutando contra as forças federalistas formadas por três mil combatentes.

João Cândido Ferreira (1864-1948), filho de Alferes João Cândido Ferreira e de dona Leocádia Maciel Ferreira, nasceu na Fazenda Taboão, propriedade de seu avô materno, o Comendador Gregório Antunes Maciel na Lapa. Diplomo-se em medicina pela Faculdade de Medicina do Rio de Janeiro em 1888. De volta a Lapa para iniciar sua vida profissional foi convidado a ingressar na política, pelo Cel. Joaquim Lacerda, quando em 1892 torna-se Prefeito da Lapa. Ainda era prefeito em 1894 quando sua cidade foi sitiada pelos federalistas, aceitando chefiar o corpo médico da legislação legalista sob insistência do coronel Antônio Gomes Carneiro, chefe militar das forças legalistas no Paraná. Em 1896 elegeu-se Deputado ao Congresso Legislativo Estadual pelo Partido Republicano, e em 1896, e Deputado Federal em 1901. Em junho de 1903, 
aceita o convite de Vicente Machado, então candidato a Presidência do Estado, candidatando-se à vice-presidência do Estado. Eleitos para o período 1904- 1907, assumiu a presidência do Estado por várias vezes até a morte de Vicente Machado em março de 1907. Foi eleito pelo Partido Republicano Federal, para a sucessão governamental no pleito de 20 de outubro de 1907. Contudo, uma manobra política arquitetada por Pinheiro Machado forçou sua renúncia. Por conta desse episódio Cândido Ferreira deixa a vida política, renunciando a chefia do Partido Republicano e à Presidência do Estado, dedicando-se a vida profissional. Como médico, clinicou na Santa Casa de Misericórdia e como professor ocupou a cátedra de Clínica Médica na Universidade do Paraná. Em dezembro de 1931 foi nomeado membro do Conselho Consultivo do Estado quando da Interventoria de Mário Tourinho, permanecendo no órgão do até fevereiro de 1932, quando Manoel Ribas já havia assumido a Interventoria federal. Candidata-se a o governo do Estado em janeiro de 1935 pelo PSN mas, mais uma vez seu nome foi preterido. Recebendo apenas 5 dos 30 votos da Assembleia do Estado, contra 20 votos de Manoel Ribas e cinco votos em branco, saiu vitorioso o partido do Interventor. Foi membro da Associação Médica do Paraná (AMP), entidade que nasceu em 1933, fruto da fusão de outras associações de classe: a Sociedade de Medicina, a Sociedade Médica dos Hospitais e o Sindicato Médico do Paraná. Pertenceu também à Academia Nacional de Medicina, do Rio de Janeiro e à Academia de Letras do Paraná. Era cunhado de Ottoni Maciel, o qual era casado com Maria da Glória do Amaral, a qual, por sua vez, era irmã de Josepha do Amaral, com quem João Cândido se casara.

Josepha do Amaral Ferreira era irmã de Victor Ferreira do Amaral, médico, intendente municipal de Curitiba, jornalista, capitão-médico da Guarda Nacional, diretor do Ginásio Paranaense, diretor do Departamento Sanitário do Estado, diretor da Instrução Pública, professor, deputado estadual e federal, vice-presidente do Estado do Paraná, fundador e primeiro reitor da Universidade Federal do Paraná, diretor da Faculdade de Medicina. Sua família tinha vínculo estreito com David dos Santos Pacheco, Barão dos Campos Gerais. Victor era afilhado do Barão e da Baronesa. Teve os filhos Alceu, Leônidas, João Cândido, Murilo, Agenor, e uma única mulher, Julinda, gêmea de seu irmão Celso. Julinda casou o advogado, depois juiz e desembargador, Francisco Cunha Pereira, de tradicional família mineira. Um de seus filhos é médico e ex-conselheiro do Tribunal de Contas João Cândido Cunha Pereira. Casou-se com Cleony Pinto Pereira com quem teve três filhos, todos consultores técnicos no Tribunal de Contas. João Cândido da Cunha Pereira Filho, formado em Direito pela Universidade Federal do Paraná, foi consultor técnico do Tribunal de Contas onde é atualmente aposentado, tem escritório de advocacia em Curitiba, casado com Maria da 
Graça Pacheco, consultora técnica do Tribunal de Contas. José Francisco da Cunha Pereira foi consultor técnico do TC, falecido em 26 de junho de 2013. Eduardo Luiz Pinto da Cunha, consultor técnico e atualmente aposentado pelo Tribunal de Contas. Isso é, enquanto foi conselheiro, João Cândido colocou todos os filhos no Tribunal de Contas.

Outro filho de Francisco Cunha Pereira é Francisco Cunha Pereira Filho, o Chico Beleza, dono da Gazeta do Povo, por muito tempo o maior empresário de comunicações do Paraná. Depois do golpe de 1964, a Gazeta do Povo tornou-se uma defensora fanática do regime e sua fidelidade à ditadura militar foi recompensada com generosas verbas publicitárias do governo federal para a Gazeta e também para a TV Paranaense (canal 12) que contava com a participação acionária do empresário Roberto Marinho. A sociedade com a família Marinho foi desfeita apenas em 2002, quando o Grupo paranaense assumiu a totalidade da emissora. Nos anos seguintes foram montadas ou compradas mais sete emissoras de televisão, cobrindo todas as regiões do Estado. Era o ocupante da cadeira de número 18 da Academia Paranaense de Letras, sucedendo Manoel de Lacerda Pinto, em 1974. Era conselheiro do Atlético Paranaense. Seus herdeiros, junto com a família Lemanski, são donos do GRPCOM - Grupo Paranaense de Comunicação, que domina a RPC TV (oito emissoras de TV afiliadas à Rede Globo), os sites RPC TV, G1 Paraná, Globo Esporte Paraná, Paraná Online, os jornais Gazeta do Povo (o maior do Paraná), Jornal de Londrina, Gazeta Maringá e Tribuna, as rádios 98FM, Mundo Livre FM, Cultura FM e ainda empresas como ÓTV, HD View, Canal do Crédito e Zaag. Grupo comprou os jornais Tribuna do Paraná e o Estado do Paraná além do portal Paraná-Online, que pertenciam ao Grupo Paulo Pimentel.

A família Lacerda também se entrelaçou com outras famílias tradicionais. Joaquim Resende Correia de Lacerda nasceu no município da Lapa (PR) no dia 29 de março de 1845, filho de Manuel Correia de Lacerda e de Leocádia Cassiana Resende de Lacerda. Comerciante, durante a Guerra do Paraguai (1864-1870) foi organizador de um dos batalhões brasileiros que embarcaram para o combate. Em 1893, durante a Revolução Federalista, assumiu o comando superior da Guarda Nacional de seu município natal, atuando no treinamento dos soldados que lutaram no episódio conhecido como cerco da Lapa. Conhecido por ser um entusiasta do regime monárquico, mesmo assim recebeu o título de coronel honorário do Exército brasileiro por sua participação na luta contra os federalistas. Em 1897 foi eleito senador pelo Paraná, com mandato até dezembro de 1899. Assumindo sua cadeira no Senado, no Rio de Janeiro, então Distrito Federal, em maio do mesmo ano, passou a integrar a Comissão de Comércio, Agricultura e Indústria e Artes. Faleceu na Lapa no 
dia 12 de julho de $1905^{3}$. Seu sobrinho, Manoel de Lacerda Pinto (1893-1974), conhecido como Duca Lacerda, nasceu na Lapa, no dia 4 de dezembro de 1893, onde fez seus estudos primários. Em Curitiba cursa o secundário no Ginásio Paranaense. Em 1912 parte para São Paulo concluir os estudos superiores na Faculdade do Largo de São Francisco, bacharelando-se em Ciências Jurídicas e Sociais em 1917. Depois de formado advogou em Curitiba até 1930. Foi um dos intelectuais paranaense que assinou um manifesto de apoio ao candidato paulista Júlio Prestes, em fevereiro de 1930. Com o advento da Revolução de 1930 foi nomeado membro do Conselho Consultivo do Estado, pelo Interventor Mário Tourinho. No período de gestão da Interventoria de Manoel Ribas, Lacerda Pinto permaneceu no Conselho Consultivode janeiro a julho de 1932, quando pede exoneração do cargo. Nas eleições de maio de 1933 elege-se Deputado Federal à Assembleia Constituinte Nacional pelo Partido Social Democrático-PSD. Exerceu o mandato de deputado somente até a promulgação da Constituição, voltando a advogar. Em 1937 foi nomeado Procurador Geral do Estado, permanecendo à frente do Ministério Público até março de 1939, quando foi nomeado para o cargo de Secretário do Interior e Justiça. Em novembro de 1941 foi nomeado desembargador. Exerceu as funções de Presidente do Tribunal de Justiça de 1949 a 1952 e de 1959 a 1960. Foi membro do Tribunal Regional Eleitoral por quatro anos, ocupado também a Presidência da casa por três gestões: 1949- 1952 e na gestão 1959-1960. Aposentou-se como desembargador em 1963, por limite de idade. Em 1940 era professor titular da cadeira de Ciências Políticas do Curso de Ciências Sociais da Universidade do Paraná. De 1949 a 1950 exerceu as funções de Professor de Direito Comercial da Faculdade de Direito da Universidade Federal do Paraná. Com a fundação da Faculdade Católica respondeu pela cátedra de Direito Civil, que também exerceu na Faculdade de Ciências Econômicas. Foi membro do Círculo de Estudos Bandeirantes, do Centro de Letras do Paraná e da Academia Paranaense de Letras, na qual ocupou a cadeira $n^{\circ} 18$. Foi também membro do Instituto dos Advogados Brasileiros e da Associação dos Magistrados Brasileiros. Foi poeta e prosador, suas atividades neste campo das letras remetem ao significado de sua participação no grupo da revista Fanal. Era casado com sua prima Esther Lacerda Pinto, irmã de Flávio Supplicy de Lacerda.

Flávio Suplicy de Lacerda (1903-1983) foi engenheiro, professor e político. Nasceu na Lapa, no dia 4 de outubro de 1903. Era filho do Cel. Manoel José Correia de Lacerda e Alice Maria Suplicy de Lacerda. Estudou no Colégio Júlio Theidorico até 1915, quando passa a estudar no Colégio Militar de Barbacena (MG). Forma-se em Engenharia Civil, pela Escola Politécnica de São

\footnotetext{
${ }^{3}$ http://cpdoc.fgv.br/sites/default/files/verbetes/primeira-republica/LACERDA,\%20Joaquim.pdf
} 
Paulo, turma 1928. Sua experiência profissional tem início com o cargo de engenheiro da Prefeitura de Curitiba, onde serviu na Revolução de 1930 como oficial de equipagem de pontes no $5^{\circ}$ Batalhão de Engenharia. Em 1931 defendeu uma tese sobre o fenômeno da flambagem na Faculdade de Engenharia do Paraná, tornando-se então professor da disciplina Resistência dos Materiais. Foi também membro do Círculo de Estudos Bandeirantes, instituição responsável pela constituição de um curso de Filosofia no início da década de 1930 e especialmente interessada em formar um grupo comprometido com as questões doutrinárias e filosóficas do catolicismo. Em 1936 foi eleito, em eleição indireta, para o Conselho de Estado pelos representantes do Partido Social Democrático que tomavam assento na Assembleia Legislativa Estadual. Foi também diretor da rede de Viação ParanáSanta Catarina, presidente do Conselho Regional de Engenharia e Arquitetura (CREA - Curitiba), engenheiro-fiscal da Estrada de Ferro Monte Alegre e da Companhia de Força e Luz do Paraná. Durante a Interventoria de Brasil Pinheiro Machado, em 1946, foi Secretário de Viação e Obras Públicas. Em 1948, quando João Ribeiro de Macedo Filho era reitor da Universidade do Paraná, Flávio era vice-reitor. Em 1950, torna-se reitor da Universidade do Paraná. Militou pela sua federalização, passado a chamar-se Universidade Federal do Paraná, depois do processo de federalização iniciado pela lei $\mathrm{n}^{\circ}$ 1.250, de dezembro de 1950. Durante o regime Militar Suplicy de Lacerda foi Ministro da Educação e Cultura do governo do General Humberto Castelo Branco, quando então sancionou a lei $n^{\circ}$ 4.464/1964 que dispunha sobre os órgãos de representação dos estudantes. Tal lei, conhecida como lei Suplicy, definia a regulamentação das entidades estudantis, ao mesmo tempo em que proibia o exercício de atividades políticas em seu interior. Foi casado com Dalila de Castro Lacerda. Era cunhado de outro Conselheiro, Manoel de Lacerda Pinto, casado com sua irmã Esther Lacerda Pinto. Foi também cunhado de um dos mais abastados industriais do Paraná, David Carneiro Júnior, que se casara com sua irmã Marília Suplicy de Lacerda. Único cargo político eletivo de Supplicy de Lacerda foi a eleição indireta para o Conselho de Estado em maio de 1930 (CAMPOS, 2013).

Diferentes matrimônios integraram o "Clã da Lapa” com famílias imigrantes. David Wiedmer Neto nasceu na Lapa no dia 14 de dezembro de 1924. Filho de David Timótheo Wiedmer e de Carolina Wiedmer, casou-se em primeiras núpcias com Cleonice Lacerda Suplicy Wiedmer, com quem teve sete filhos: Tânia, Roseana, David Antônio, Clovis, Eugênio, Aloísio e Ruy. Em segundas núpcias, casou-se com Donatila Beraldi de Souza Wiedmer. David estudou no Grupo Escolar Dr. Manoel Pedro, no Internato do Ginásio Paranaense e no Colégio Paranaense, cursando Direito na Universidade do Paraná e se inscrevendo na Ordem dos Advogados do Brasil (PR) sob no 795. 
Foi professor titular da cadeira de Geografia Geral e do Brasil no Colégio Estadual General Carneiro, onde lecionou por cerca de 30 anos. Ali também ministrou aulas de História, Matemática, Organização Social e Política do Brasil (OSPB) e Química. Lecionou também no Colégio Estadual São José, onde foi diretor por dois anos. A partir de 1945, quando possuía apenas 21 anos, foi eleito vereador pela extinta UDN, expressiva votação, que o colocou em $2^{\circ}$ lugar entre os demais candidatos no resultado final das urnas da cidade. Em mais cinco eleições disputou com êxito o mesmo cargo, exercendo, assim, por 25 anos a vereança na Lapa. Disputou também o cargo de Deputado Estadual, sendo o mais votado na 10 ${ }^{\text {a }}$ Zona Eleitoral. A partir de junho de 1965 se tornou advogado da então Consultoria Geral do Estado, hoje Procuradoria Geral do Estado, onde lhe coube representação ativa e passiva do Paraná em questões de terras. Após se aposentar na Procuradoria Geral do Estado, reativou sua banca de advocacia na Lapa. Também foi membro efetivo do Instituto Histórico, Geográfico e Etnográfico do Paraná, sendo portador de um vasto arquivo sobre fatos e personagens da história da Lapa, destacando-se seus apontamento sobre a genealogia das famílias locais e efemérides lapeanas. Foi fundador do Lapa Country Clube e sócio contribuinte do Clube Lapeano e Congresso Recreativo, exercendo por várias vezes participação nas diretorias.

O patriarca da família alemã da Lapa foi Eugênio Westphalen, farmacêutico, natural de Berlim, onde nasceu a 3 de Janeiro de 1800 e chegou a Lapa em 1830. Era filho do Dr. Felippe Fernando Westphalen e de sua mulher Luiza Fischer Westphalen, nascida em Basiléa-Suíssa. Casou com Joanna Francisca Westphalen, filha Antônio Gonçalves da Silva e Anna Amália de França. Tiveram 17 filhos, como o fazendeiro Fernando Westphalen, casado com Thecla Mendes de Sá, Frederico Westphalen, engenheiro civil, casado com Agueda Pires da Silva, filha de João Pires da Silva e Cândida de Oliveira Pires, Alfredo Westphalen, casado com Adélia Netto de Mattos, Hildebrando Westphalen, medico, casado com Ottilia Carolina Molz, natural de Porto Alegre, cuja descendência leva a família Etchegoyen do Rio grande do Sul, dentre eles o General Alcides Etchegoyen e Sérgio W. Etchegoyen, atual superministro de segurança institucional do governo federal de Michel Temer (PEREIRA, 2004).

Outro filho do casal Eugênio Westphalen e Dona Joanna Francisca foi Emydio Westphalen, nascido na Lapa em 11 de novembro de 1847. Casou-se com a Sra. Januaria Carvalho de Oliveira. Em 1867, formou-se em Ciências Jurídicas e Sociais pela Faculdade de Direito de São Paulo. Seu primeiro cargo público foi o de Promotor Público em Paraíba do Sul (RJ). De volta à cidade natal, exerceu cargos de promotor e vereador. Teve importante papel no Judiciário Paranaense, tendo sido juiz Municipal de Curitiba, juiz de Direito da Comarca da Lapa e um dos primeiros desembargadores 
do Tribunal de Apelação, para o qual foi nomeado em $1^{\circ}$ de agosto de 1881 . Foi ,ainda, Deputado Provincial e Chefe de Polícia. No final da carreira, exerceu o cargo de procurador-geral da Justiça de 14 de abril de 1908 até sua aposentadoria em 10 de novembro de 1911. Colaborou com a imprensa da época, com ênfase à defesa da implantação de um governo democrático no país. Colaborou com os jornais "Opinião Liberal", "Commércio do Paraná", "Livre Paraná", "A Reforma" e "Província do Paraná". Participou da Revolução Federalista entre a década de 1880 e 1892. Em 1884 integrou o governo revolucionário de Nossa Senhora do Desterro, atual cidade de Florianópolis (SC). Este envolvimento acabou gerando imbróglios políticos à época em que sustentou uma decisão de um juiz de primeiro grau, alheio aos interesses republicanos de Vicente Machado, o qual iniciou certa perseguição a Westphalen, alegando que suas convicções liberalistas iam contra a Monarquia e a República, que tantas vezes o haviam designado para importantes cargos. Exilou-se na Argentina e voltou ao Brasil devido à anistia assinada pelo Presidente Prudente de Morais. Nomeado ao cargo de Procurador-Geral de Justiça de 1908 até 1911. Faleceu em Curitiba, em 17 de março de 1923. É patrono do Fórum de Rebouças.

No século XX, grupos políticos oriundos da Lapa continuam com presença marcante no cenário paranaense. A família Lupion, de origem espanhola, primeiramente abriu um comércio na Lapa. João Lupyon y Troya, morou na cidade da Lapa, mas na ocasião do cerco àquela localidade teve o seu comércio destruído, mudando-se depois para Jaguariaíva. Ali trabalhou na construção de uma parte da ferrovia São Paulo-Santa Catarina. Após o término da construção da estrada, retornou à condição de comerciante com a instalação de uma padaria. A família mudou-se para Piraí do Sul e parte dos seus filhos, dentre eles Moysés Lupion, casaram-se com membros de tradicionais famílias da região dos Campos Gerais. Moysés casou-se com Hermínia Borba Rolim, neta do Coronel Telêmaco Borba, político em Tibagi. Moisés Lupion, sempre filiado ao PSD, foi eleito governador do Paraná em 1947 e senador em 1954. Seus descendentes continuam exercendo altos cargos no Estado. Seus netos são Abelardo Lupion, ex-deputado federal (DEM) e atual presidentes da COHAPAR e José Lupion Neto, atual presidentes da COHAB no governo Greca e casado com a defensora pública Josiane Fruet Bettini Lupion. Seus bisneto é o atual líder do governo Cida Borguetti o deputado estadual Pedro Lupion (DEM). Diversos casamentos e eventos da elite curitibana são realizados no Castelinho do Batel, da família Lupion.

O "Neyismo" foi sua última expressão do "Clã da Lapa" no século XX, mostrando sua resistência e transformação histórica. Ney Amintas de Barros Braga nasceu em Lapa no dia 25 de julho de 1917, filho de Antônio Lacerda Braga e de Semíramis Barros Braga. Seus pais pertenciam a 
famílias tradicionais e influentes da Lapa. João Pereira Braga e Josefa Gonçalves da Silva foram os primeiros sesmeiros a se estabelecer com morada efetiva nos Campos Gerais (WESTEPHALEN, 1991, p. 178). Seu avô materno, José Amintas da Costa Barros, morreu em combate em 1894, durante o cerco de Lapa pelos federalistas gaúchos, o episódio militar mais importante ocorrido no Paraná no curso da Revolução Federalista (1893-1895). Seu pai, Sr. Antonio Braga criou, juntamente com outros sócios uma construtora de obras, a Aranha S.A., visando participar da construção de obras públicas a convite do governador Manoel Ribas. Ney Braga fez carreira militar iniciando seus estudos nessa área na Escola Militar do Realengo no Rio de Janeiro, entre 1935 e 1937. Aos vinte e dois anos casou-se com Maria José Munhoz da Rocha, filha do ex-governador Caetano Munhoz da Rocha (1920-1928). Iniciou a sua carreira política por intermédio do cunhado Bento Munhoz da Rocha Neto, que era filho e genro de governadores do Estado. Ney Braga foi prefeito de Curitiba, deputado federal, governador do Estado do Paraná em duas gestões: 1961-1965 e 1979-1982, ministro da Agricultura, ministro da Educação, senador, presidente da Itaipu Binacional. Quando foi governador, Ney Braga fez uma administração atenda aos interesses familiares. Para a Secretaria da Educação e Cultura chamou seu primo, Mário Braga Ramos. Um deputado estadual da época era seu outro primo Fabiano Braga Côrtes e outro primo Caetano Braga Côrtes, presidente do BANESTADO. No segundo governo, seu filho Caetano Rocha Braga foi do Departamento de Compras da COPEL. Seu outro filho Antônio Lacerda Braga era funcionário da ALEP. Seu genro Luiz Henrique Pinto foi da Telepar. Outro genro, Oscar Alves casado com Silvia Braga Cortes, foi Secretário de Estado. O presidente do Banestado foi Jucundino Furtado, sócio de membros da família. No Tribunal de Contas, José de Almeida Pimpão foi auditor, sogro de Antonio Lacerda Braga. Seu primo João Antônio Braga Cortes era conselheiro do TCE-PR (pai da vereadora Julieta Reis). Responsável pela construção pelo governo de Escolas foi Guilherme Lacerda Braga, irmão de Ney. No Banco de Desenvolvimento do Paraná - BADEP -, o Diretor-Presidente era Luiz Antonio Fayet (sobrinho de Ney). Na Procuradoria Geral Estado estava Sérgio Botto de Lacerda, sobrinho de Flávio Suplicy de Lacerda, também parente de Ney Braga (OLIVEIRA, 2001). Apesar de perder influência do poder estadual de lá para cá, a família Braga ainda tem membros em diversos aparelhos do Estado, como no caso do atual presidente do Tribunal de Justiça do Paraná (TJ-PR) o desembargador Renato Braga Bettega, e os vereadores de Curitiba Julieta Reis e Felipe Braga Côrtes (que também é funcionário do TCE-PR), filho de Fabiano Braga Côrtes, em seu quinto mandato como vereador de Curitiba, mantendo-se como um dos mais atuantes políticos da capital. 
A partir da década de 1980, novos grupos passaram a integrar os núcleos de poder estatal, principalmente forças política do Norte do Paraná, como os Richa e os Barros. Mesmo assim, encontramos descendentes das famílias tradicionais lapeanas em diversos espaços de poder atualmente.

$\mathrm{Na}$ Operação Lava-Jato, por exemplo, pelos menos dois operadores são destas famílias. O procurador Carlos Fernando dos Santos Lima é filho do ex-deputado estadual da ARENA Osvaldo dos Santos Lima, promotor, vice-prefeito em Apucarana e presidente da Assembleia Legislativa do Paraná, em 1973, no auge da ditadura, quando as pessoas não podiam votar e nem debater livremente. O pai de Carlos Fernando, assim como os irmãos, Luiz José e Paulo Ovídio, também atuaram como procuradores no Paraná. O avô foi Luiz dos Santos Lima, comerciante e juiz em São Mateus do Sul, na época do coronelismo local. A família aparece na Genealogia Paranaense (V1, 543 e V4, 437) situada nas oligarquias da Lapa entre latifundiários escravistas, família aparentada ao Barão dos Campos Gerais e outros membros da classe dominante tradicional desta

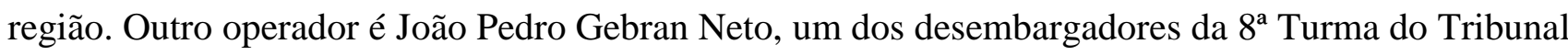
Regional Federal da $4^{\text {a }}$ Região (TRF-4), relator do processo conhecido como "caso triplex", em segunda instância, cujo réu é o ex-presidente Lula. O desembargador que atua no Rio Grande do Sul é filho de Antonio Sebastião da Cunha Gebran e neto de João Pedro Gebran, ex-diretores-gerais da Assembleia Legislativa do Paraná nos anos 1950 e 1970. João Pedro casou em 1924 com Francisca Cunha, filha do coronel Francisco Cunha, prefeito da Lapa na República Velha. O avô do coronel Cunha era o comendador Manuel Antonio da Cunha, primeiro prefeito da Lapa, em 1833, casado com a filha do $1^{\circ}$ capitão-mor da Lapa, o português Francisco Teixeira Coelho ${ }^{4}$.

O entrelaçamento das famílias certamente ajudou na concentração dos membros desta floresta genealógica em diferentes posições estratégicas do Estado e da sociedade. A história das famílias tradicionais da Lapa é toda interligada por matrimônios. Aqueles conhecidos nomes de ruas e de praças muitas vezes dividem um mesmo documento de identidade ou certidão de casamento e nascimento. Quase todas remontam ao período de colonização do país, atravessando o período Imperial, República Velha, Estado Novo e chegando até os dias atuais, já as demais iniciando no período Imperial. Logo, são famílias estruturadas em um padrão de longa duração, sempre ocupando posições dominantes no cenário social. Os novos ingressos e as novas formas da classe dominante se estruturam com o que permanece. A dinâmica de "entradas e saídas não altera a existência de alguns núcleos de permanência e de continuidade ao longo dos séculos” (OLIVEIRA, 2001, p.342).

\footnotetext{
${ }^{4}$ https://www.brasildefato.com.br/2017/08/10/berco-de-ouro-mentalidade-autoritaria-a-arvore-genealogica-da-lava-jato/
} 
Membros das famílias fundadoras passam a se entrelaçar formando uma complexa floresta genealógica. Todas as famílias com origens históricas no latifúndio escravista da Lapa - Teixeira, Ferreira, Amaral, Pacheco, Lacerda, Correa, Braga, Rezende, Cunha, Suplicy, Pereira, Coelho, Westphalen, entre outras - eram aparentadas entre si. A classe dominante formada na Lapa tinha tropeiros, fazendeiros, ervateiros, comerciantes que passaram a investir na formação educacional, especial em direito, medicina, engenharia, humanidades e na área eclesiástica, impulsionando fortes laços de matrimônio entre eles, ocupando importantes cargos públicos no Estado, além de significativa retenção do poder político, jurídico e econômico.

Elas formam o que poderíamos denominar "Clã da Lapa”, um grupo complexo de famílias, de estrutura mais ou menos descentralizada, composta por sesmeiros, fazendeiros, tropeiros, padres, advogados, médicos, engenheiros, senhores do mate, etc, entreçaladas entre si. Ao analisar a origem e o desenvolvimento da classe dominante lapeana percebemos diversos membros ocupando a direção do Estado. Estas famílias ricas e poderosas facilitaram amplamente o acesso aos descendentes e parentes aos grupos dirigentes, inclusive por meio da formação de elites administrativas, econômicas, políticas, jurídicas e eclesiais, formando redes que se reproduzem por matrimônios entre as famílias, sempre muito próximas, socializadas por meio do mando e relações de exercício de autoridade.

Seria possível compreender a ação destas famílias como uma espécie de clã, o "clã da Lapa", uma verdadeira instituição política, capaz de se perpetuar por várias gerações, com semelhantes trajetórias sócio-históricas. Os povoadores da região são atravessados por parentesco, formando uma tradição de união e solidariedade, de cooperação das famílias contíguas e aparentadas, com alta endogamia das suas descendências. O compadrio também ampliou as conexões entre as famílias, criando laços novos de afinidade interpessoal. Ser descendente dos fundadores, ter por padrinho o capitão-mor, coronel ou barão engrandece o espírito de família e linhagem. Seria possível compreender a ação destas famílias como uma verdadeira instituição política capaz de se perpetuar por várias gerações. Fica evidente que o peso da origem familiar no acesso à propriedade e cargos públicos, atestando que o parentesco contribui decisivamente para o exercício do poder e manutenção de privilégios, cultivando o mesmo habitus, modo de viver e pensar.

Quando estava em decadência econômica pelo fim do mate, no século XX essas famílias passaram a fazer alianças matrimoniais com membros de outras famílias dominantes, principalmente de Paranaguá e Curitiba. Outro elemento de transformação no século XX é que o diploma passou a 
ser condição para manutenção do status que desfrutavam. Muitos foram bacharéis ocupantes de cargos do poder estatal. Como as nomeações eram feitas por indicações, as famílias dominantes indicavam-se entre si. A trajetória das famílias da classe dominante da Lapa elucida como a família funciona como uma instituição matriz na transmissão de poder, influência e riqueza, cruzando gerações, apesar de não ser um processo uniforme no tempo e no espaço.

\section{Referências}

ANDREAZZA, M. L. Olhares para a Ordem Social na Freguesia de Santo Antônio da Lapa 17631798. Associação dos Estudos de População, UFPR. 2016. Disponível em http://www.abep.org.br/publicacoes/index.php/anais/article/viewFile/1140/1103

ALVES, Alessandro Cavassin. A produção antroponômica para a política: casos no Paraná, Brasil. Revista NEP - UFPR (Núcleo de Estudos Paranaenses), Curitiba, v.3, n.3, p.136 155, agosto 2017. Disponível em: http://revistas.ufpr.br/nep/article/view/54327/33047

BEGA, M. T. S. Sonho e invenção do Paraná: geração simbolista e a construção de identidade regional. São Paulo. Tese (Doutorado em Sociologia). Universidade de São Paulo, 2001.

FERREIRA, J. C. V. O Paraná e seus municípios. Maringá: Memória Brasileira, 1996.

GUTIÉRREZ, H. Fazendas de gado no Paraná escravista. Topoi: Revista de História, Rio de Janeiro, n. 9, p. 102-127. p. 102, 2004.

LACERDA NETO, A. V. O magnífico reitor: biografia de Flávio Suplicy de Lacerda, ensaio de histórico da UFPR de 1949 a 1971. Curitiba: Instituto Histórico, Geográfico e Etnográfico paranaense, 1988.

MACHADO, B. P. Contribuição ao estudo da história agrária do Paraná - I: formação da estrutura agrária tradicional dos Campos Gerais. Boletim da Universidade Federal do Paraná, Curitiba (3): 1 21, junho 1963.

OLIVEIRA, R. C. O Silêncio dos Vencedores: genealogia, classe dominante e estado no Paraná. Curitiba: Moinho do Verbo, 2001.

- Na teia do nepotismo: sociologia política das relações de parentesco e poder político no Paraná e no Brasil. Curitiba: Insigth, 2012.

PEREIRA, C.N. Genealogia tropeira Rio Grande do Sul. Século XIX e XX, volume II. 2004. Disponível em http://www.genealogiacorrea.com.br/GENTROP7.pdf

RIBEIRO, L. C. O mandonismo local e o movimento republicano. História: questões \& debates, Curitiba, v. 3, n. 4, p. 65-85, jun. 1982. 
VALLE, Marília. Nupcialidade e fecundidade das famílias da Lapa. 1770-1829. São Paulo, Tese [Doutorado], USP, 1983.

WACHOWICZ, R. C. 1977. História do Paraná. Curitiba: Vicentina, 1977.

WESTPHALEN, Cecília M.; MACHADO, Brasil P.; BALHANA, Altiva P. Nota prévia ao estudo da ocupação da terra no Paraná moderno. Boletim da Universidade Federal do Paraná. Curitiba, Departamento de História, nº 7, p.1-52, 1968.

WESTHEPHALEN, C. M. et all. IN: Dicionário histórico-biográfico do estado do Paraná. Curitiba, Editora do Chain/Banestado, 1991. 